\title{
Vital dye labelling of Xenopus laevis trunk neural crest reveals multipotency and novel pathways of migration
}

\author{
Andres Collazo ${ }^{1, *}$, Marianne Bronner-Fraser ${ }^{2}$ and Scott E. Fraser ${ }^{1}$ \\ 1Division of Biology, Beckman Institute, 139-74, California Institute of Technology, Pasadena, CA 91125, USA \\ ${ }^{2}$ Developmental Biology Center, University of California, Irvine, CA 92717, USA \\ ${ }^{*}$ Author for correspondence
}

\section{SUMMARY}

Although the Xenopus embryo has served as an important model system for both molecular and cellular studies of vertebrate development, comparatively little is known about its neural crest. Here, we take advantage of the ease of manipulation and relative transparency of Xenopus laevis embryos to follow neural crest cell migration and differentiation in living embryos. We use two techniques to study the lineage and migratory patterns of frog neural crest cells: (1) injections of DiI or lysinated rhodamine dextran (LRD) into small populations of neural crest cells to follow movement and (2) injections of LRD into single cells to follow cell lineage. By using non-invasive approaches that allow observations in living embryos and control of the time and position of labelling, we have been able to expand upon the results of previous grafting experiments. Migration and differentiation of the labelled cells were observed over time in individual living embryos, and later in sections to determine precise position and morphology. Derivatives populated by the neural crest are the fins, pigment stripes, spinal ganglia, adrenal medulla, pronephric duct, enteric nuclei and the posterior portion of the

\section{INTRODUCTION}

The neural crest is a population of cells, unique to vertebrates, that migrates extensively along restricted pathways and forms many diverse derivatives. Most recent studies of neural crest development have utilized avian embryos. Tissue grafting and ablation experiments show that avian neural crest cells emigrate from the dorsal region of the neural tube during or shortly after its closure, migrate considerable distances and differentiate into cell types ranging from neurons, adrenomedullary cells and glia, to pigment cells, chondrocytes and odontoblasts (Le Douarin, 1982; Hall and Horstadius, 1988). Neural crest cell populations from different rostrocaudal axial levels differ in their patterns of migration and ranges of derivatives; for example, cranial neural crest cells form the connective tissue of the face and cranial sensory ganglia, whereas trunk neural crest cells form pigment cells and elements of the peripheral ner- dorsal aorta. In the rostral to mid-trunk levels, most neural crest cells migrate along two paths: a dorsal pathway into the fin, followed by presumptive fin cells, and a ventral pathway along the neural tube and notochord, followed by presumptive pigment, sensory ganglion, sympathetic ganglion and adrenal medullary cells. In the caudal trunk, two additional paths were noted. One group of cells moves circumferentially within the fin, in an arc from dorsal to ventral; another progresses ventrally to the anus and subsequently populates the ventral fin. By labelling individual precursor cells, we find that neural tube and neural crest cells often share a common precursor. The majority of clones contain labelled progeny cells in the dorsal fin. The remainder have progeny in multiple derivatives including spinal ganglion cells, pigment cells, enteric cells, fin cells and/or neural tube cells in all combinations, suggesting that many premigratory Xenopus neural crest precursors are multipotent.

Key words: DiI, developmental potential, clonal analysis, LRD, Xenopus neural crest, vital dye labelling, neural crest vous system (reviewed by Le Douarin, 1982; Hall and Horstadius, 1988). Given these behaviors, two major issues concerning the neural crest are the developmental potential of individual neural crest cells and the exact timing and pathways of their migration.

Recent cell-labelling techniques applied to avian and mouse embryos offer insights into important questions of cell migration and lineage. Focal or global labelling of the premigratory neural crest with the cell autonomous vital dye, DiI, have been used to define better the timing and pathways of neural crest cell migration (Serbedzija et al., 1989, 1990; Lumsden et al., 1991). These results together with those for grafts of heterospecifically or radioactively labelled neural tubes demonstrate that neural crest cells undergo an orderly pattern of migration (Weston and Butler, 1966; Le Douarin, 1982). Injection of fluorescent dextrans into individual cells permits determination of the range of descendants formed by a single progenitor (Gimlich and 
Braun, 1986). Experiments using this methodology show that many neural crest cells share a common progenitor with dorsal neural tube cells, suggesting that the neural crest is not a segregated population within the neural tube (Bronner-Fraser and Fraser, 1989; Serbedzija et al., 1992). Furthermore, many of the labelled clones that descend from either premigratory (Bronner-Fraser and Fraser, 1989; Serbedzija et al., 1992) or migrating (Fraser and BronnerFraser, 1991) neural crest cells encompass multiple derivatives. These and similar findings tracing cell lineages with recombinant retroviruses (Frank and Sanes, 1991) demonstrate that the fate of neural crest cells is not fixed at early migratory stages. Clonal analysis of avian neural crest cells in vitro similarly has shown that individual cells from both cranial (Baroffio et al., 1991; Sextier-Sainte-Claire Deville et al., 1992) and trunk (Sieber-Blum and Cohen, 1980) levels can form multiple derivatives.

Although most recent studies on the neural crest have concentrated on higher vertebrates, earlier experiments utilized amphibian embryos (Hall and Horstadius, 1988). Because of their hardiness, ease of manipulation, relative transparency at late stages and extensive use in general developmental studies, amphibians offer some distinct advantages for studying questions of neural crest cell migration and differentiation. Classical studies utilized tissue ablation as well as intra- or interspecific transplants, in which donor and host cells were distinguishable based on nuclear or cytoplasmic differences (DuShane, 1935, 1938; Twitty and Bodenstein, 1941). The results revealed some of the derivatives that normally arise from the neural crest (DuShane, 1938) and elucidated some of the interactions necessary for the formation of neural derivatives, such as the requirement for interactions with pharyngeal endoderm in order to form cartilage (Hall and Horstadius, 1988). In vivo observations of neural crest migration have been limited to already differentiated pigment cells; for example, it has been possible to follow migration of pigment cells in the salamander, Ambystoma mexicanum (Keller and Spieth, 1984) because their superficial locations makes them easy to film with cinemicroscopy.

Despite detailed knowledge of the early development of Xenopus laevis, relatively little is known about the neural crest in this species. Some neural fold or tube transplantations, in which donor and host cells are distinguishable (Sadaghiani and Thiebaud, 1987; Krotoski et al., 1988), as well as tissue ablation (Seufert and Hall, 1990), have been used to study the development of Xenopus neural crest. Most of these studies have concentrated on the cranial neural crest (Sadaghiani and Thiebaud, 1987; Seufert and Hall, 1990). By grafting either X. borealis (Thiebaud, 1983) or fluorescent dextran-labelled X. laevis (Krotoski et al., 1988) neural tubes into unlabelled $X$. laevis hosts and examining the distribution of labelled donor cells in fixed sections, two major pathways of migration were revealed: (1) a dorsal pathway into the fin and (2) a ventral path along the neural tube and the notochord (Krotoski et al., 1988). An additional minor pathway comprised of presumptive pigment cells was observed under the epidermis. Clonal analysis of Xenopus neural crest cells in culture, revealed that some pigment precursor cells are bipotent, giving rise to both xanthopores and melanophores (Akira and Ide,
1987), suggesting that, as in avian embryos, individual Xenopus neural crest cells might be multipotent.

In the present study, we apply advanced imaging techniques to the neural crest in Xenopus to follow individual cells and their descendants as they migrate and differentiate. Two approaches are used: (1) injections of DiI or lysinated rhodamine dextran (LRD) into small populations of neural crest cells to follow the patterns of cell movement and (2) injections of LRD into single cells to follow cell lineage. These improved techniques use no grafting and permit the timing and pathways of migration to be defined exactly by direct observation of the labelled progeny cells. This contrasts with previous studies in which the migration and differentiation of the neural crest cells were inferred from their positions after fixation and processing. Using new technologies, we not only confirm previously observed pathways, but also identify formerly unknown derivatives of the Xenopus neural crest and novel migratory pathways into the ventral fin. With regard to developmental potential, our results demonstrate that, as in birds, many Xeno pus neural crest cells are multipotent.

\section{MATERIALS AND METHODS}

\section{Embryos}

Xenopus laevis eggs fertilized in vitro were acquired as previously described (Krotoski et al., 1988). Embryos were staged according to the normal table of Nieuwkoop and Faber (1967). Stage 15 to 23 Xenopus embryos were dejellied manually prior to injections, which were carried out in either full-strength Steinberg's solution supplemented with $5 \mathrm{mM}$ calcium (for lysinated rhodamine dextran; LRD) or in 15\% amphibian Ringer's solution (for 1,1-dioctadecyl-3,3,3',3'-tetramethylindocarbo-cyanine perchlorate; DiI). Embryos were immobilized in trenches cut into $2 \%$ agar gelled in the bottom of Petri dishes.

\section{Microinjection of Dil}

A $0.5 \%$ stock solution of the lipophilic dye 1,1-dioctadecyl3,3,3',3'-tetramethylindocarbo-cyanine perchlorate (DiI, Molecular Probes) was made up in $100 \%$ ethanol. It was injected at this concentration or diluted in $0.3 \mathrm{M}$ sucrose, immediately before injection, to working concentrations of 0.05 to $0.01 \%$. Quartz micropipets broken to a tip of approximately $20 \mu \mathrm{m}$ were backfilled with DiI solution and attached to a Picospritzer (General Valve). DiI injections were achieved by inserting a micropipet into the dorsal neural folds or tube of the trunk, containing presumptive neural crest cells and expelling small amounts of dye solution. A Zeiss dissecting microscope was used to observe the injection. A range of 50 to 500 cells was labelled per injection. The labelled region encompassed the neural tube, tissue dorsal to it and, occassionally, a few somite cells. Labelling was performed in the trunk region at three primary locations (indicated on Fig. 1): rostral (at or just posterior to the branchial arches), middle and caudal-most portion of the embryo.

\section{Microinjection of lysinated rhodamine dextran (LRD)}

The Xenopus embryos were mounted on the stage of an epifluorescence microscope (Zeiss UEM) and viewed (Nikon MPlan LLWD 20× Objective) with oblique lighting from a fiber optic illuminator. Thin-walled aluminosilicate micropipets (resistance 25-40 Mohm) were filled at the tip with lysinated rhodamine dextran (LRD, Molecular Probes; $100 \mathrm{mg} / \mathrm{ml}$ ) and then back filled with 1.2 M LiCl (Wetts and Fraser, 1988). A Huxley-style manipulator (Camden Instruments) held a pipet used to impale a cell in the dorsal neural tube by briefly 'ringing' the electrode with the 


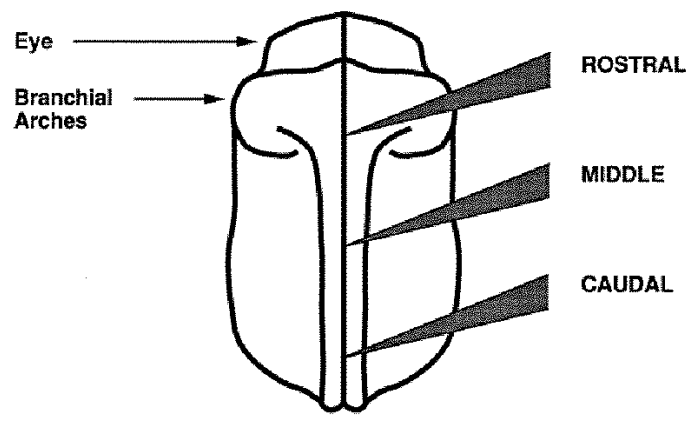

Fig. 1. Stage 21 Xenopus embryo showing the three axial levels in the trunk (rostral, middle and caudal) where injections were made. The region of the prospective trunk extends from the level of the branchial arches to the caudal-most point of the embryo. Diagram is of embryo viewed from the dorsal surface.

negative capacitance control. A membrane potential typically ranging from -5 to $-30 \mathrm{mV}$ served as a reliable measure of successful cell impalement; the potential was low, probably due to a large tip potential in our dye-filled electrodes. After iontophoretic injection, the injected cell was visualized by its fluorescence to determine that just a single cell was labelled and to observe its morphology.

\section{Preparation of living embryos for imaging after dye injection}

After DiI or LRD injection, embryos were placed in fresh Petri dishes containing 15\% amphibian Ringer's solution supplemented with gentamycin. Living embryos were anesthetized $(0.2 \%$ methanesulfonate in 15\% Ringer's; Sigma A-5040), placed in Petri dishes containing shallow depressions in $2 \%$ agar and gently coverslipped to facilitate observation of labelled cells. Labelled cells were visualized on a Zeiss epifluorescence microscope using either Nikon or Zeiss objectives ranging from 5 to $40 \times$. A rhodamine filter set was used to visualize the dye. Data were recorded digitally and onto a video optical disc recorder (OMDR) using a lightintensifying camera (RCA or Hamamatsu SIT) and image processor (Imaging Technology 151), using the VidIm software package (Belford, Stollberg, Fraser unpublished). Typically, each animal was observed at least three times over the course of 6 days (between stages 28 and 48). Some animals were placed in agar grooves and recorded using time-lapse cinematography $(5: 1$ or 10:1) for up to 12 hours at intervals ranging from 30 seconds to 2 minutes. Afterwards, embryos were fixed for either cryostat or plastic sectioning.

\section{Cryostat sections}

Embryos receiving focal injections of DiI were fixed in $4 \%$ paraformaldehyde $/ 0.25 \%$ glutaraldehyde in $0.1 \mathrm{M}$ phosphate buffer solution (PB) overnight at $4^{\circ} \mathrm{C}$. Embryos subsequently were washed in $0.1 \mathrm{M} \mathrm{PB}$ and soaked in a $15 \%$ sucrose solution for 12 hours at $4^{\circ} \mathrm{C}$. They were embedded in a $15 \%$ sucrose $/ 7.5 \%$ gelatin (Oxoid) solution for 2 hours at $37^{\circ} \mathrm{C}$ and then rapidly frozen in liquid nitrogen. Embryos were sectioned at a thickness of 20-25 $\mu \mathrm{m}$ on a Zeiss Microm cryostat. Sections were mounted in Gel/Mount (Biomeda Corp.) and covered with glass coverslips for viewing as described above.

\section{Plastic sections}

LRD-labelled embryos were fixed overnight in $4 \%$ paraformaldehyde, washed in PB and dehydrated to $95 \%$ ethanol. Embryos were infiltrated and then embedded in glycol methacrylate (Historesin LKB, Sweden). The blocks were sectioned serially at a thickness of $15 \mu \mathrm{m}$ on a Historange microtome (LKB) and sec- tions were mounted on subbed slides. Sections were viewed as described above.

\section{Paraplast sections}

Some LRD-labelled embryos were fixed and washed as described above for plastic sections. They subsequently were dehydrated to $100 \%$ ethanol. Embryos then were transferred through two Histosol washes, infiltrated and embedded with Paraplast Plus (Oxford) in a vacuum oven. The blocks were sectioned serially at a thickness of $10 \mu \mathrm{m}$. Sections were viewed as described above.

\section{Confocal microscopy and data processing}

A sampling of embryos labelled with LRD were preserved overnight in $4 \%$ paraformaldehyde, washed with $\mathrm{PB}$, dehydrated in methanol and mounted in 2:1 benzyl benzoate: benzyl alcohol (BB/BA) for observation. These embryos were placed in glasswelled slides and imaged using the Bio-Rad MRC-600 laser scanning confocal system attached to a Zeiss Axiovert 35 microscope using the CoMOS version 2.08 software. This technique allowed clear observations of the location and morphology of the deeper, labelled cells without the need for sectioning. Confocal images of a through-focus set of optical sections (z-series) were stored on Bernoulli discs and reconstructed on an IRIS workstation using VoxelView.

All images collected using the VidIm software package and most of the confocal images were processed using Photoshop on a MacIntosh IIFX and prints were produced on a Nikon CP3000 Thermal Printer.

\section{RESULTS}

To map the frog neural crest and follow its pattern of migration, small populations of neural fold cells have been labelled with either DiI or LRD in the trunk region of embryos. To assess the developmental potential of single neural crest cells, individual cells were injected with LRD. DiI offers the advantages of bright, vital labelling of small groups of cells; LRD is a more difficult dye to introduce, but offers a means to label unambiguously single cells and their progeny. Labelled cells are usually detectable up to stage 48. Most injections have been performed at stages 18 to 22 , at which time the neural folds have closed, the optic vesicles have evaginated and branchial arches are expanding. As shown in Fig. 1, injections are made in one of three locations in the trunk: (1) the rostral trunk, immediately caudal to the branchial arches, (2) the mid-trunk and (3) the caudal-most portion of the embryo. Injections into the rostral and mid-trunk give similar migratory patterns and are presented collectively. The phenotypes that arise from the labelled neural crest cells have been identified at the end of the experiment by both their position and their morphology.

\section{Migration patterns and fates of rostral and mid- trunk neural crest cells \\ Dil-labelling}

In confirmation of the results obtained in the grafting experiments of Krotoski and colleagues (1988), we find that rostral and mid-trunk neural crest cells migrate from the dorsal neural tube on two primary routes: (1) a dorsal pathway into the fin and dorsal pigment stripe and (2) a ventral pathway circumnavigating the neural tube and notochord. In 

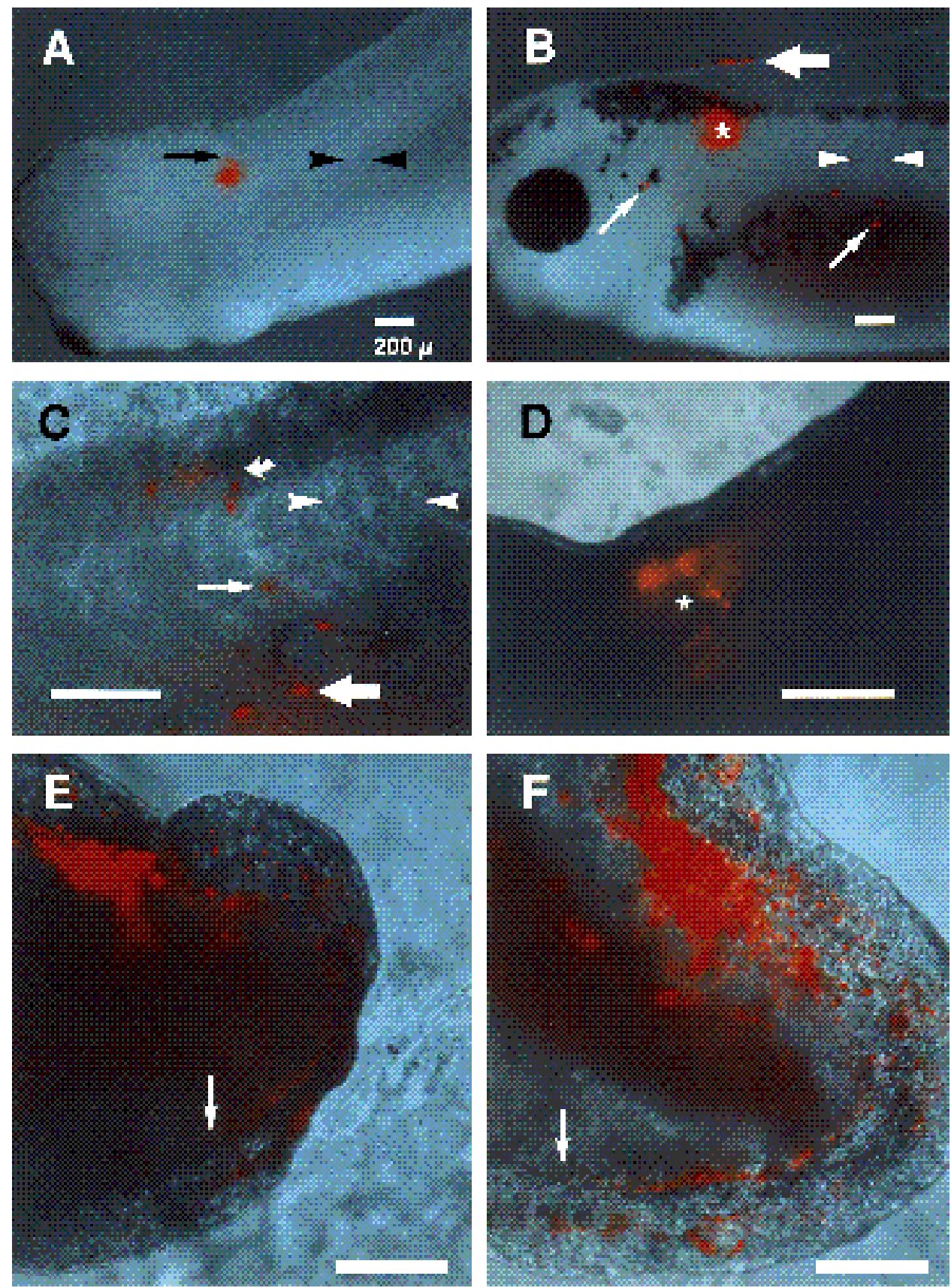

Fig. 2. Living DiI-labelled embryos showing neural crest migration in the rostral, mid and caudal trunk regions. Embryos are oriented so that rostral is to the left and dorsal is to the top. (A) Stream of cells (arrow) migrating from the site of injection dorsally into the prospective dorsal fin of a stage 29 embryo injected rostrally with DiI at stage 21. (B) Labelled fin (large arrow) and pigment cells (small arrows) in a stage 40 embryo. Injection site is marked with an asterix. (C) Cells migrating along the ventromedial pathway in a single file (small arrow), along the caudal half of the myotome and invading the lateral pigment stripe (large arrow), which forms bilaterally at the ventral portion of the myotomes. The curved arrow points to a process extending dorsally from a neuron. The stage 37/38 embryo received a mid-trunk injection. (D-F) Same embryo viewed at stages 27,33 and 36 , injected unilaterally into the caudal neural fold at stage 17. (D) At stage 27, labelled cells have spread only a short distance from the injection site (asterix). (E) Labelled cells have migrated rostrocaudally within the dorsal fin (d) and then in an arc to the ventral fin (v) by stage 33; arrow indicates the furthest extent of migration within the ventral fin. $(F)$ Labelled cells in the ventral fin have extended further rostrad (arrow) by stage 36 . Arrowheads indicate the boundaries of a myotomal segment. Scale bars, $200 \mu \mathrm{m}$. addition, there is a minor lateral pathway under the epidermis, followed by presumptive pigment cells.

Because it is possible to control the time and position of DiI injection, this approach permits the determination of the time of initiation and duration of migration. Emigration of labelled neural crest cells from the neural tube occurs between stages 24 and 30, with cells in the rostral region initiating migration before those in the mid-trunk. Typically, the injection site remains visible as a brightly labelled, continuous region of the neural tube, spreading across one to three myotomal segments (Fig. 2A). Before stage 25 , few if any cells emigrate from the injection site $(n=6)$. By stage 29, some labelled cells (less than twenty) have migrated dorsally from the point of injection and are observed entering the dorsal pathway at the base of the prospective dorsal fin region (arrow, Fig. 2A). Some labelled cells have migrated ventrally to the ventral margin of the neural tube and can be observed clearly in tissue sections (arrow, Fig. 3A).

Most cell migration along the dorsal, ventral and lateral pathways takes place between stages 30 and 40. Throughout these stages, labelled cells invade the fin; some of these contribute to the dorsal pigment stripe (Fig. 2B). Cells moving ventrally along the neural tube and notochord reach the position of the prospective spinal ganglia by stage 32 to $34(n=20)$, and exhibit neuronal processes by stage 38 (Fig. 2C). The majority of the cells that populate the lateral pigment stripes move singly along a path between the 

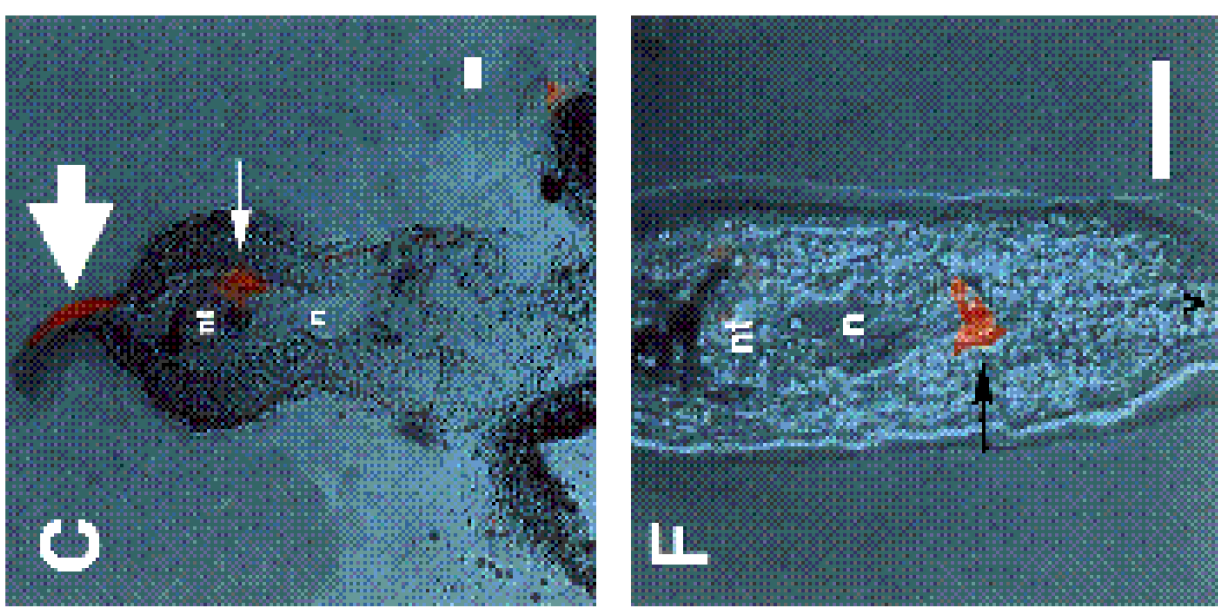

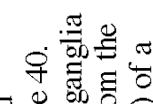

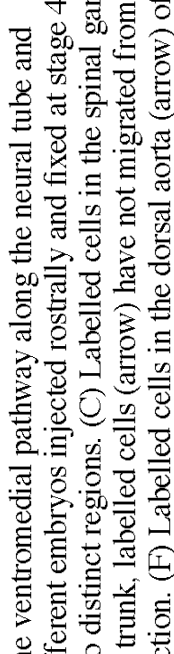

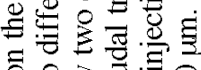
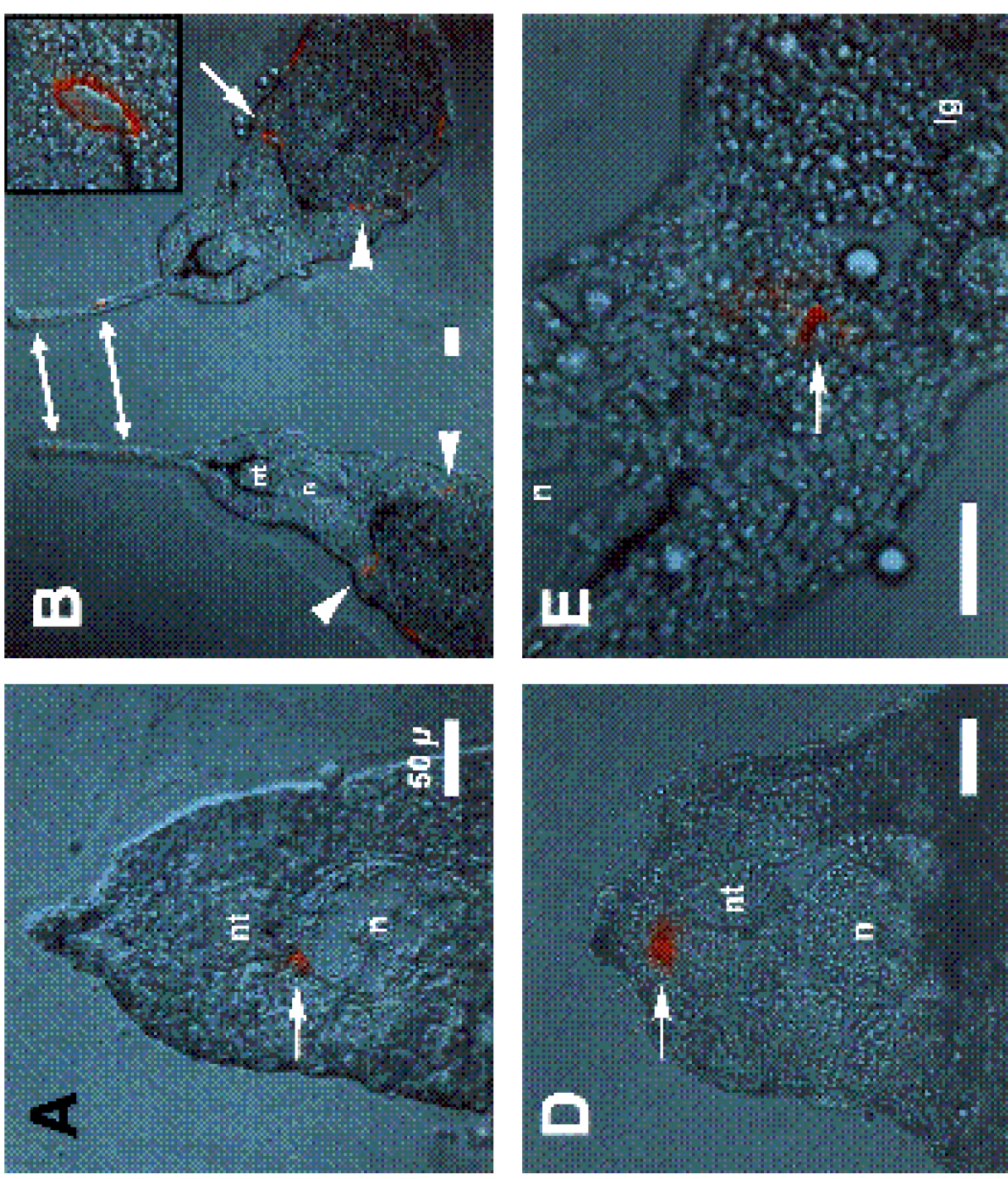

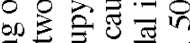
过

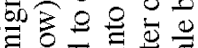

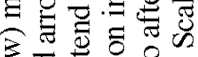

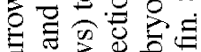

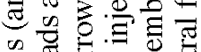

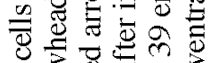

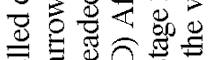
च ज乎 亩 $\unlhd .0$ 家录目击 कृ 을 势 웡 券 $\overline{8} . \exists$.

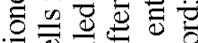
\%

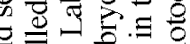

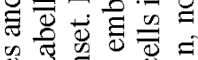
证. 舟

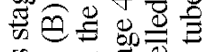

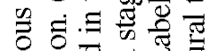
음효

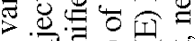

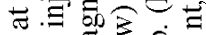

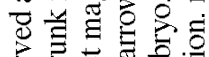

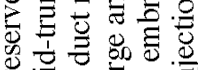

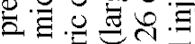

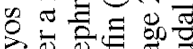

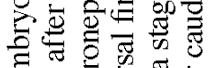
है बे ते

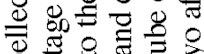

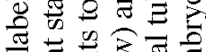

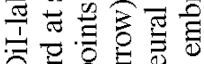

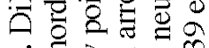

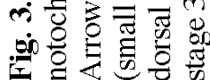


ventral portion of the somites and the yolk to reach their final positions (Fig. 2B,C).

Derivatives of the DiI-labelled cells are scored at or after stage 41 , when the bulk of migration is completed. Labelled derivatives include the neural tube, dorsal fin, spinal ganglia and the lateral pigment stripes (Figs 2B, 3C). In addition, labelled cells are visible ( $n=6$ embryos) in the adrenomedullary region as well as in the epithelial walls of the pronephric duct, where they encompass most of the duct's circumference (Fig. 3B). This is the first demonstration of a neural crest contribution to the pronephric duct and the adrenal medulla of Xenopus.

\section{LRD-labelling}

To permit individual cells to be imaged more clearly, we repeated the experiments described above using intracellular injection of LRD to mark individual or small groups ( $\leq$ 8 cells) of neural fold and/or neural crest cells $(n=100)$. When more than one cell is labelled, the LRD-labelled cells are in direct contact, initially contained within a single myotomal segment.

The better cellular resolution offered by LRD-labelling permits us to follow both cellular translocations and shape changes. At stage 29, a few fin cells are observed immediately dorsal to the injection site and undifferentiated prospective pigment cells are grouped together close to the site of injection (Fig. 4A). By stage 33, the pigment cells begin to adopt their branched morphology and to move apart (Fig. 4B). Between stages 35 (Fig. 4C) and 41 (Fig. $4 \mathrm{D}, \mathrm{E})$ the pigment cells contain melanin granules and continue their motility although they are nearing their final positions. Most pigment cells complete migration by stage 41. Interestingly, many of the pigment cells in the head reach their position by migrating from the rostral trunk along a deep ventral pathway from which they emerge to settle under the head epidermis. In addition to pigment cells, LRD-label is observed in spinal ganglion cells, neural tube cells and fin cells as described above for DiI.

\section{Extent of dispersion of rostral cells}

The distance over which labelled cells disperse differs among migratory pathways and varies with injection size. Along the ventral pathway, larger DiI injections $(\sim 500$ labelled cells) result in labelled cells that disperse rostrally and caudally 4-8 myotomal segment lengths; cells from smaller injections ( $\sim 50$ cells) disperse 2-3 segments either rostrally or caudally, but generally not both. Different cell types demonstrate different degrees of dispersion; for example, labelled pigment cells are separated by up to 8 myotomal segment lengths, whereas labelled neural tube and spinal ganglion cells are usually separated by less than 2 myotomal segment lengths (Fig. 2C). Along the dorsal pathway, the distance labelled cells disperse varies between 2 and 6 myotomal segment lengths, again depending upon the size of the injection and the cell type. This variation is not surprising, since pathway choice may depend on the initial cell position and the larger injections may encompass larger numbers of emigration sites. The dispersal of LRD-labelled cells supports this explanation since they disperse less than DiI injections. Groups of cells with similar fates tend to migrate relatively close together and disperse within 1 to 3 myotomal segment lengths after completion of migration (Fig. 4). However, groups of labelled cells with different fates (e.g. pigment cells and fin cells; neuronal cells and fin cells) could be as much as 6 to 8 segments apart (Fig. 4A-C).

\section{Migration patterns and fates of caudal trunk neural crest cells}

\section{Dil labelling}

Initiation of neural crest cell migration in the caudal trunk begins later than in the rostral level, with few labelled cells observed outside of the dorsal neural tube prior to stages 27 to 32 (Fig. 3D; $n=2$ embryos sectioned transversely at stage 26 and $n=6$ at stage 29). Except for this delay, DiIlabelled cells migrate similarly to and populate most of the same derivatives as those described above for rostral and mid-trunk injections.

Caudal trunk injections do not result in labelled cells in the adrenomedullary and pronephric regions, which are labelled heavily after rostral or mid-trunk injections. However, labelled cells are observed in the enteric ganglia, dorsal aorta and ventral fin (Fig. 3E,F), sites which are unlabelled after rostral or mid-trunk injections. Labelled cells occupy enteric ganglia or the aorta by stage 39; they enter the ventral fin somewhat later. The labelled enteric cells are probably neurons and/or glia because they have processes while those in the dorsal aorta appear to be endothelial cells based on their flattened morphology and position. Our study provides the first unambiguous demonstration of a neural crest contribution to enteric, dorsal aorta and ventral fin cells in Xenopus.

DiI-labelled neural crest cells migrate into the ventral fin along two pathways which have not been described previously (summarized in Fig. 8). The tail tip pathway extends along the dorsal surface of the neural tube or within the dorsal fin, around the tip of the tail and into the ventral fin (seen in 40 embryos). The enteric pathway extends directly ventrad toward the anus and enters the ventral fin. Because the enteric pathway is more easily seen after LRD labelling, we defer discussion of it to the following section. The tail tip pathway is most clearly observed by imaging the same embryos at three different stages (Fig. 2D-F). Migration begins at stage 27 (Fig. 2D), with labelled cells moving rapidly around the tail tip and into the ventral fin between stages 28 and 32; over the next few stages the cells disperse rostrally in the ventral fin to a varying extent (Fig. 2E,F). As in the dorsal fin, labelled cells in the ventral fin are localized in two streams: the first near the base of the fin; the second near the edge of the fin (Fig. 2E,F; compare to Fig. 3B).

\section{LRD-labelling}

LRD injections confirm the two pathways of migration of neural crest cells into the ventral fin and permit the timing of the migration to be analyzed. Labelled cells migrating along the tail tip pathway appear first in the ventral fin, reaching their most rostral extent as early as stage 29 , before the fin has formed fully (Fig. 5A). This appears to be due both to the earlier onset of migration along the dorsal pathway and a faster rate of cell migration. Since tail elongation 

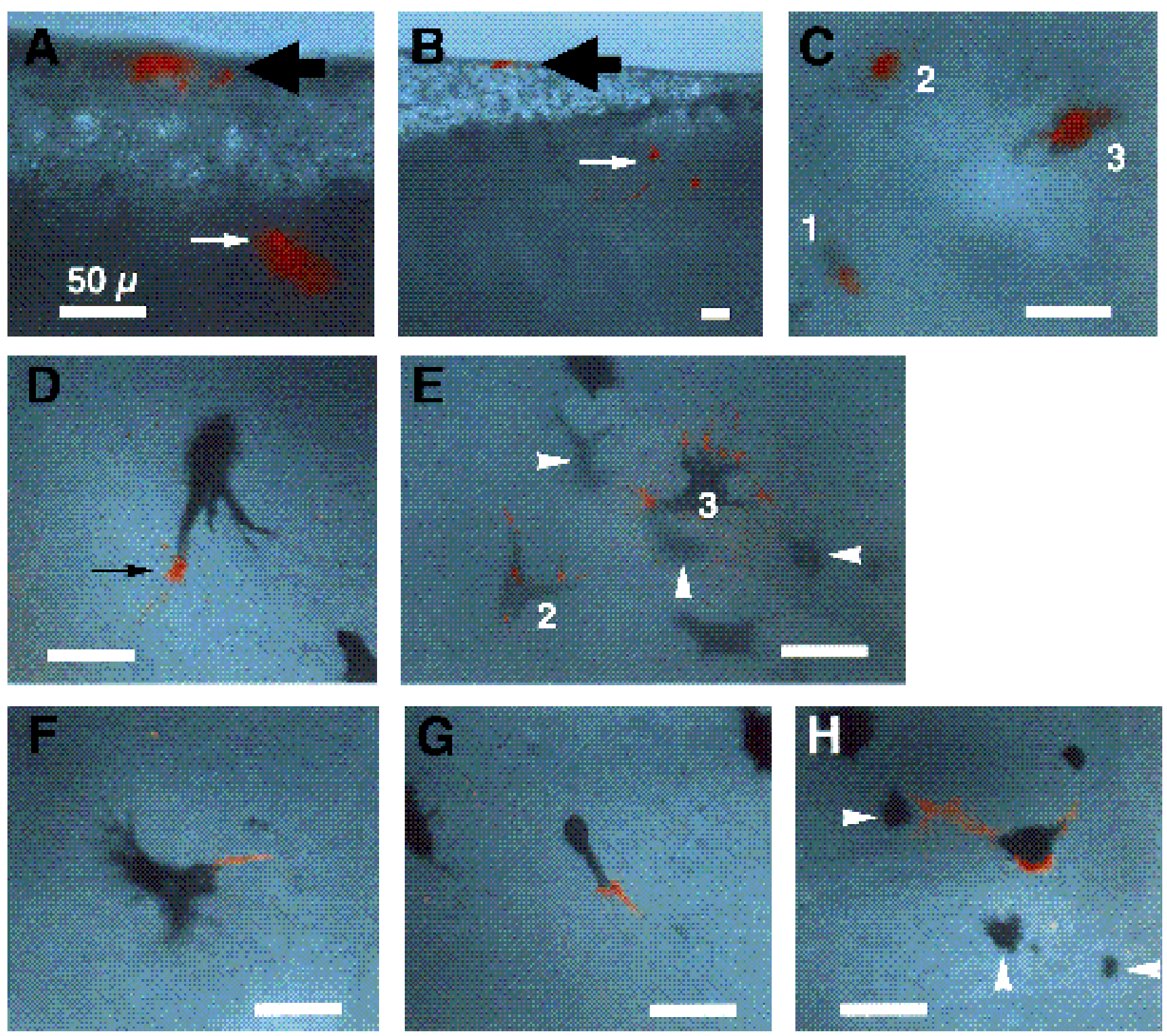

Fig. 4. A single cell injected with LRD (rostral; stage 21) gives rise to labelled pigment and fin cells. The same pigment cells are depicted at 5 different stages in a living embryo. (A) Prospective pigment cells (small white arrow) are undifferentiated and grouped together, close to the site of injection at stage 29. Also, there are labelled cells in the fin (large black arrow). (B) Three pigment cells (small arrow) have processes and have moved apart from each other by stage 33. In addition, the distance between the fin cells (large arrow) and pigment cells has increased. (C) By stage 35, pigment cells are close to their final locations, just dorsal and caudal to the right eye, and are beginning to undergo melanogenesis. The cells are numbered 1 to 3 for identification at later stages. (D) Pigment cell 1 has large amounts of melanin but the dye is still visible in one of the processes (arrow) at stage 41; it has moved away from cells 2 and 3. (E) Pigment cells 2 and 3 have four and six cytoplasmic processes, respectively, at stage 41. Arrowheads point to three unlabelled pigment cells that can be seen next to cell 3 at later stages. (F) Cell 1 viewed at stage 42 . Cytoplasmic processes are not necessarily oriented in the same direction as the melanin-containing processes. $(\mathrm{G}, \mathrm{H})$ Cells 2 and 3 , respectively, viewed at stage 42 . These labelled cells have spread more than $200 \mu \mathrm{m}$ apart, yet the three unlabelled pigment cells (arrowheads) are still near to cell 3 . Rostral is to the right, dorsal to the top and the scale bars equal $50 \mu \mathrm{m}$.

is minimal at stage 29 , this faster migration cannot be due solely to a bulk movement of cells caused by the extensive morphogenesis and elongation of the tail. Migration along both pathways continues as late as stage 46 (Fig. 5B).

Labelled cells migrating along the enteric path $(n=5)$ emerge from the neural tube before stage 33, initiate their migration along the deep ventral pathway and progress ventrally to the enteric region. Some of these cells remain in the prospective enteric region in the hindgut (Fig. 5C), while others continue their migration to populate the ventral fin between stages 41 and 46 (Fig. 5D). With time, labelled cells are no longer visible in the enteric region. Two possible explanations for this transient appearance are that: (1) most of the labelled cells are in the process of migration and eventually leave the area as they move toward their final destinations and/or (2) the cells in this 

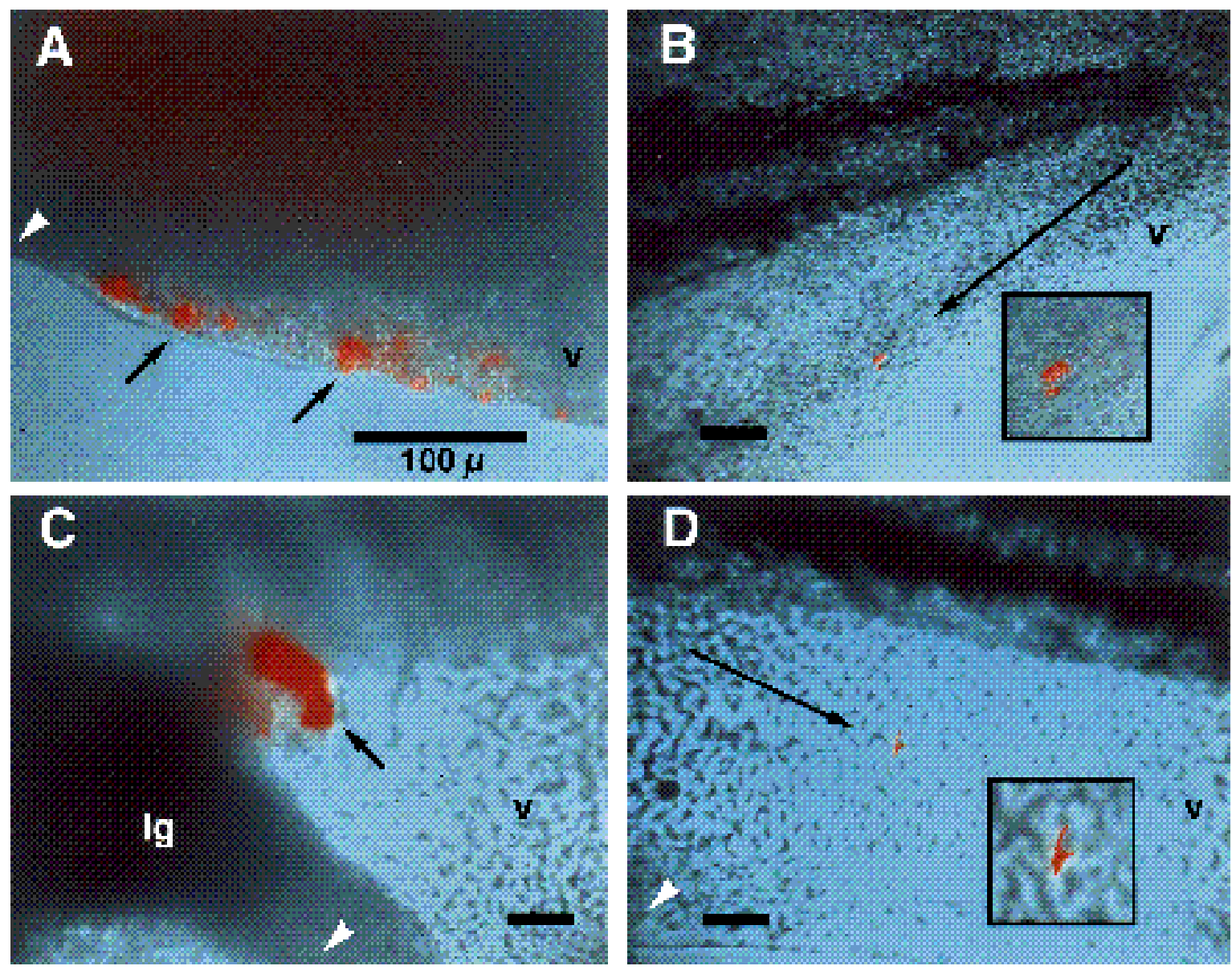

Fig. 5. Caudal trunk injections of LRD; all embryos but A initially contained a single labelled cell. Labelled progeny cells migrate into the enteric region and/or ventral fin of living embryos. (A) In an embryo viewed at stage 29, labelled cells (arrows) extend from the dorsal fin in an arc to the ventral fin. (B) Secretory cells in the ventral fin of a stage 42 embryo; arrow indicates the route of migration. The inset shows the same cells at higher magnification. (C) Cells in the prospective enteric region of a stage 41 embryo. (D) Mesenchymal cell in the ventral fin of a stage 42 embryo; arrow indicates the route of migration. The inset shows the same cell at higher magnification. lg, lower gut; v, ventral fin. Arrowheads point to anus. Rostral is to the left and the scale bars equal $100 \mu \mathrm{m}$.

region continue to divide rapidly, thereby diluting the LRD label.

\section{Extent of dispersion of labelled cells}

For comparably sized injections, caudal neural crest populations exhibit more extensive dispersion along the rostrocaudal axis (up to 12 segments) than neural crest in the rostral and mid-trunk regions. The greater rostrocaudal dispersion of neural crest cells in the caudal region partially reflects the extensive morphogenesis of the embryonic tail, which undergoes a greater degree of elongation than does the head and trunk. Accordingly, fin cells are the most dispersed cell type. However, time-lapse movies reveal that active migration also accounts for their dispersion.

\section{Developmental potential of individual neural crest cells}

Because the LRD labels single cells, it offers a direct means to test the range of phenotypes arising from one precursor. Of the 78 clones in which we injected individual cells, 52 were entirely located within the fin. Although most of these 'fin-only' clones appear to be epithelial (epidermal) cells and, hence, not of neural crest origin, some of the LRDlabelled fin cells appear to be neural crest-derived secretory cells. At the early stages injected, the neural tube and prospective neural crest cells are superficial and abut the epidermis, explaining why epithelial cells are sometimes labelled. The clones that do not unambiguously give rise to neural crest cells are not considered further.

Position and morphology have been used to classify the phenotypes of the labelled cells as ganglionic, enteric, pigment or fin cells. Even deep cells (near the midline) could be seen in living embryos. Some cells can be classified as neurons based on their long processes and these cells typically appear in small clusters of approximately 2 to 8 cells (Fig. 6). However, we are often unable to distinguish labelled neurons from glia unequivocally in living animals. The identification of cell type is facilitated by analyzing plastic sections of fixed animals (Fig. 6C-F). In living embryos, pigment cells are easily identifiable by their subepidermal position and deposits of melanin granules. Without clearing, dye label could only been seen in regions of the cell where there was no melanin (Fig. 4D-H). However, in preserved and cleared whole-mount preparations, 
it is possible to visualize the extensive branching of melanin-containing pigment cells by using the laser scanning confocal microscope (Fig. 7A,B). Three-dimensional reconstructions from confocal microscope optical sections make it possible to see the three-dimensional extent of pigment cell processes (Fig. 7C).

In the fin, two morphologically distinct types of neural crest-derived cells are observed: (1) presumptive secretory
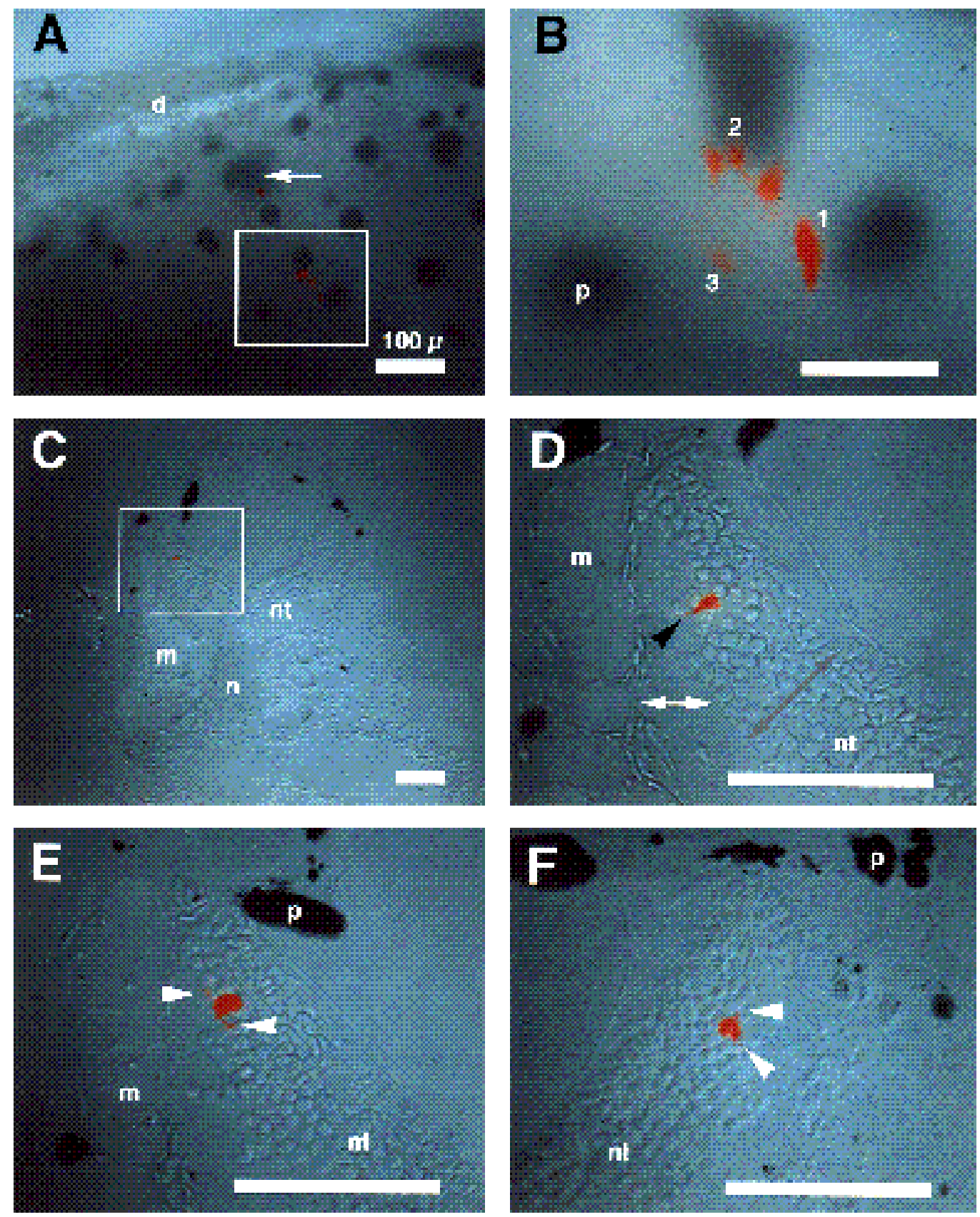

Fig. 6. LRD injected into a single rostral neural tube cell shows that a common progenitor exists for neural tube and neural crest cells; moreover, the progeny are distributed bilaterally. (A) Labelled neural tube cells (enclosed by white box) and presumptive pigment cell (arrow) in a living stage 47 embryo. The labelled cells are at different focal planes. (B) Higher magnification of the box in A shows that some cells have neuritic processes, consistent with the possibility that they are neurons. Three of the labelled cells are numbered for identification in sections. (C-F) Transverse sections through the same embryo as in B after fixation at stage 47. (C,D) Cell 1 viewed at low and high magnification, respectively, is within the neural tube (nt) and appears to be a unipolar neuron; an arrowhead indicates its neurite. The double-headed white arrow indicates the extent of the white matter in the neural tube while the double-headed gray arrow indicates the extent of the gray matter. (E) Cell 2 appears to be a bipolar neuron with two neuritic extensions (indicated by arrowheads) and can be seen in this more caudal section. (F) Cell 3 also has two neurites (indicated by arrowheads) and is on the opposite side of the neural tube in this most caudal section. nt, neural tube; $n$, notochord; $\mathrm{m}$, muscle; $\mathrm{p}$, pigment cell; $\mathrm{d}$, dorsal fin. Rostral is to the right in A and B; scale bars, $100 \mu \mathrm{m}$. 

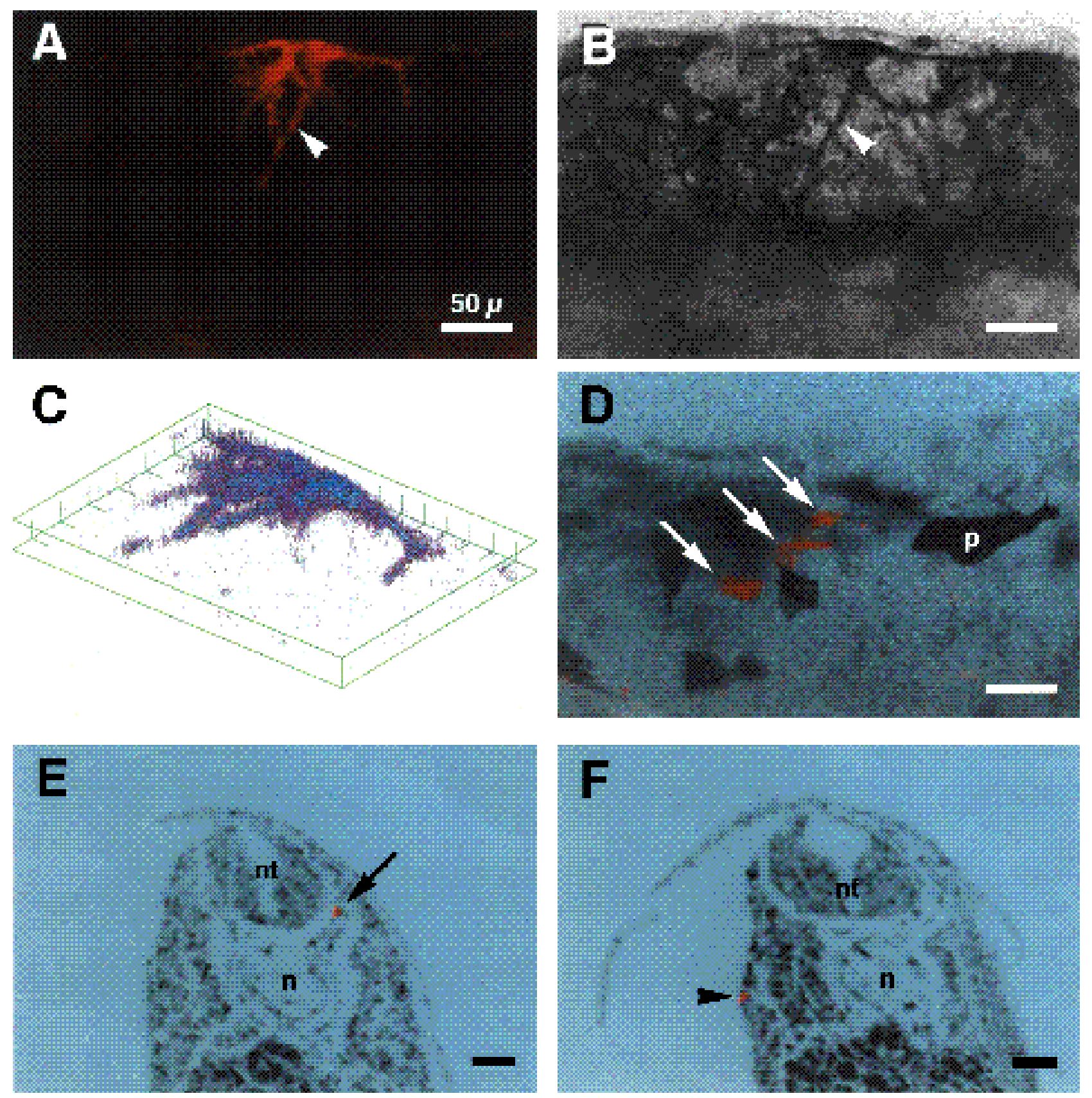

Fig. 7. Multipotent clones arising from LRD injected into individual neural crest cells at the rostral and mid-trunk levels. (A-D) An embryo fixed and cleared at stage 41 and viewed in whole mount, which had labelled fin and pigment cells. (E-F) An embryo containing labelled spinal ganglion and pigment cells fixed at stage 33 and sectioned transversely. (A,B) Pigment cell viewed by fluorescence (A) and bright-field (B) in the scanning laser confocal microscope, located rostral to the fin in the dorsal portion of the head. Note the numerous LRD-labelled processes (arrowheads) also contain melanin. (C) Three-dimensional rendering of the pigment cell in A and B rotated obliquely, illustrating the thinness of the cell. Blue points are optically denser than purple ones. Each tic represents $20 \mu \mathrm{m}$. (D) Three fin cells (arrows) from the same embryo as A-C located toward the base of the fin. (E) Labelled cell in the spinal ganglion (arrow). (F) Labelled pigment cell (arrowhead) that is on the opposite side of the embryo and in a more caudal section. nt, neural tube; $\mathrm{n}$, notochord; p, pigment cell; scale bars, $50 \mu \mathrm{m}$.

cells, which are oval (as determined using optical sectioning with the laser scanning confocal microscope) and contain vesicles (Figs 5B, 7D), are the most common cell type labelled and (2) mesenchymal cells (Fig. 5D), which are abundant in the fins and presumably provide structural support.

\section{Many premigratory trunk neural crest cells are multipotent}

In 24 clones, the phenotypes of the cells could be classified as neural tube cells and/or neural crest derivatives such as spinal ganglion, pigment, enteric and fin cells. Singlecell injections yield final clone sizes that tend to be small, 
Table 1. Phenotypes of clones from single cell injection

\begin{tabular}{|c|c|c|c|c|c|c|c|}
\hline $\begin{array}{l}\text { Embryo } \\
\text { identity no. }\end{array}$ & Neural* & Ganglion & $\begin{array}{l}\text { Neural } \\
\text { tube }\end{array}$ & $\begin{array}{l}\text { Pigment } \\
\text { cells }\end{array}$ & $\begin{array}{c}\text { Dorsal } \\
\text { fin }\end{array}$ & $\begin{array}{l}\text { Ventral } \\
\text { fin }\end{array}$ & $\begin{array}{l}\text { Enteric } \\
\text { region }\end{array}$ \\
\hline \multicolumn{8}{|l|}{ ROSTRAL } \\
\hline 1 & $X$ & & & $\mathrm{X}$ & & & \\
\hline 2 & $X$ & & & $X$ & $X$ & & \\
\hline 3 & & & & $\mathrm{U}$ & $X$ & & \\
\hline 4 & $X$ & & & $X$ & $X$ & & \\
\hline 5 & & & & $\mathrm{X}$ & & & \\
\hline 6 & $X$ & & $\mathrm{X}$ & $\mathrm{X}$ & & & \\
\hline 7 & & & & $X$ & $X$ & & \\
\hline 8 & $\mathrm{U}$ & & & & & & \\
\hline 9 & $X$ & $\mathrm{U}$ & $X$ & $\mathrm{X}$ & $X$ & & \\
\hline 10 & & & & $X$ & $\mathrm{X}$ & & \\
\hline 11 & $\mathrm{U}$ & & & & $\mathrm{X}$ & & \\
\hline 12 & $X$ & $X$ & & $X$ & & & \\
\hline 13 & & & & $\mathrm{X}$ & $\mathrm{X}$ & & \\
\hline 14 & $\mathrm{U}$ & & & $X$ & $X$ & & \\
\hline 15 & & & & $\mathrm{X}$ & $X$ & & \\
\hline \multicolumn{8}{|l|}{ CAUDAL } \\
\hline 16 & & & & & $\mathrm{X}$ & & \\
\hline 17 & $X$ & & & & $\mathrm{X}$ & $\mathrm{X}$ & $X$ \\
\hline 18 & $\mathrm{U}$ & & & & & $X$ & $X$ \\
\hline 19 & $\mathrm{U}$ & & & & & $X$ & \\
\hline 20 & & & & $\mathrm{U}$ & & $\mathrm{X}$ & \\
\hline 21 & & & & & & $\mathrm{X}$ & \\
\hline 22 & $\mathrm{U}$ & & & $\mathrm{X}$ & $\mathrm{X}$ & & \\
\hline 23 & & & & & $X$ & & $\mathrm{X}$ \\
\hline 24 & & & & $X$ & & & \\
\hline 25 & & & & $X$ & $\mathrm{X}$ & & \\
\hline 26 & $\mathrm{U}$ & & & & & & \\
\hline
\end{tabular}

$\mathrm{X}$, identified by phenotype and position; $\mathrm{U}$, identified solely by position. *The category neural includes ganglion and/or neural tube.

ranging from 2 to 16 cells. Because the dye may be diluted by prolonged mitosis in some progeny cells, this clone size may be an underestimate. Most of these clones contain multiple derivatives (Table 1), suggesting that precursor cells are multipotent. The most common types of multipotent clones contain pigment and fin cells (Figs 4, 7A-D); pigment and neuronal cells (Figs 6, 7E,F); or pigment, ganglionic and fin cells. Three embryos had labelled progeny cells in the spinal ganglia, together with other derivatives (i.e. pigment cell in Fig. 7F). The number of labelled cells within individual ganglia is typically small, ranging from 2 to 4 . Labelled progeny cells $(n=6)$ with neuritic processes are evident in the grey matter of the neural tube and can be observed in the living embryo as well as in sections (Fig. $6)$. These often are found in clones containing neural crest derivatives such as pigment cells (Fig. 6A) or spinal ganglion cells. These results suggest that many neural crest cell precursors are multipotent and often share a common lineage with some neural tube cells, as has been found in the chick (Bronner-Fraser and Fraser, 1989). Interestingly, neural tube (Fig. 6C-F) and neural crest cells (Fig. 7E,F) sometimes are localized on both the left and right sides of the embryo.

As the pathways of migration vary at different axial levels, so do the range of derivatives formed by the multipotent clones (Table 1). Rostral trunk injections tend to give rise to labelled cells in the dorsal fin, neural tissue and pigmented regions. Caudal trunk injections produce labelled cells in these three locations, as well as in the ventral fin and enteric ganglia.

\section{Changes in morphology of clonally related cells with time}

Since one can follow the same labelled cells over the course of several days, dynamic aspects of cell differentiation and shape changes can be recorded. Most of the differentiation and migration of neural derivatives occurs between stages 28 to 34 . Most pigment cells migrating along the ventral pathway undergo melanogenesis at stage 35 (Fig. 4) and differentiation is complete by stage 41 . Fin cells differentiate as late as stage 42 (Fig. 5B,D); by stage 46, no further differentiation is visible from phenotypically unspecialized labelled precursor cells. The stage of differentiation in the rostral, mid and caudal trunk regions correlates with the end of migration in these regions.

Early undifferentiated cell morphology could not be correlated with future fate, but the pathways of migration are predictive of the range of possible fates. Labelled cells that never emigrate from the neural tube form neurons and/or glia. Those that migrate along the dorsal pathway form only pigment, dorsal fin and/or ventral fin cells. Labelled cells that migrate along the ventral pathway form neurons/glia, pigment and/or ventral fin cells.

The migration and differentiation of pigment cells is particularly easy to monitor because of their superficial location and melanin content. They are very dynamic, slowly separating from one-another as well as quickly extending and retracting processes. Fig. 4 shows three pigment cells viewed at three different stages of development, illustrating extensive changes in both cell shape and melanin localization. 
A
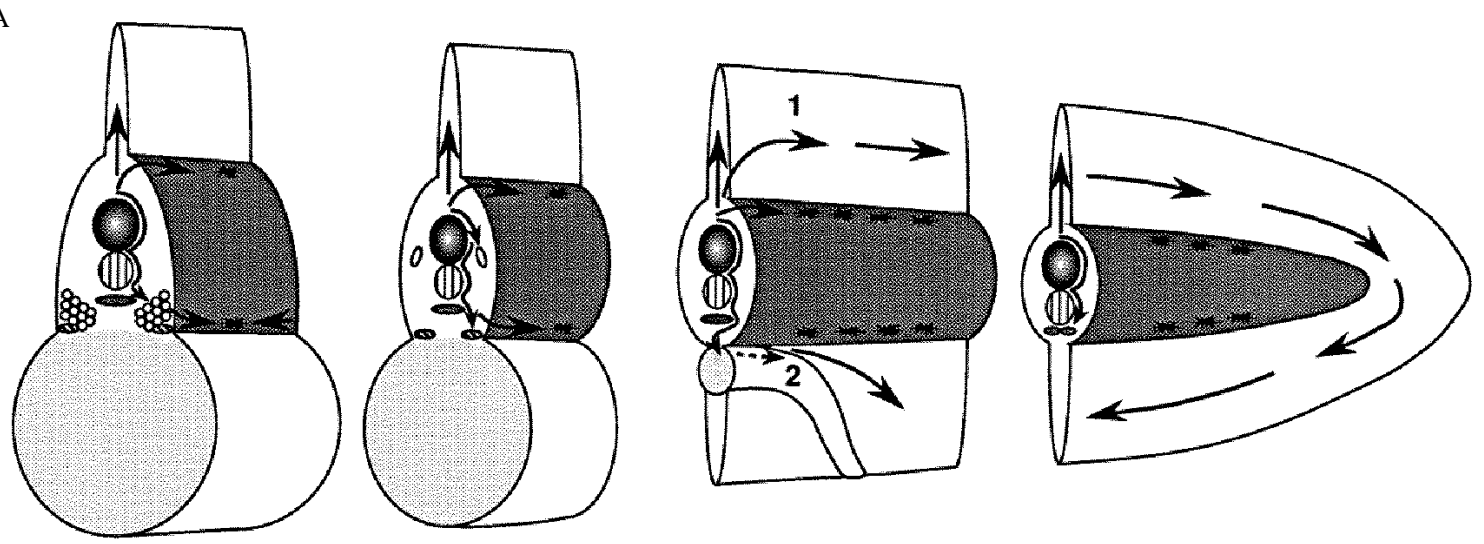

B

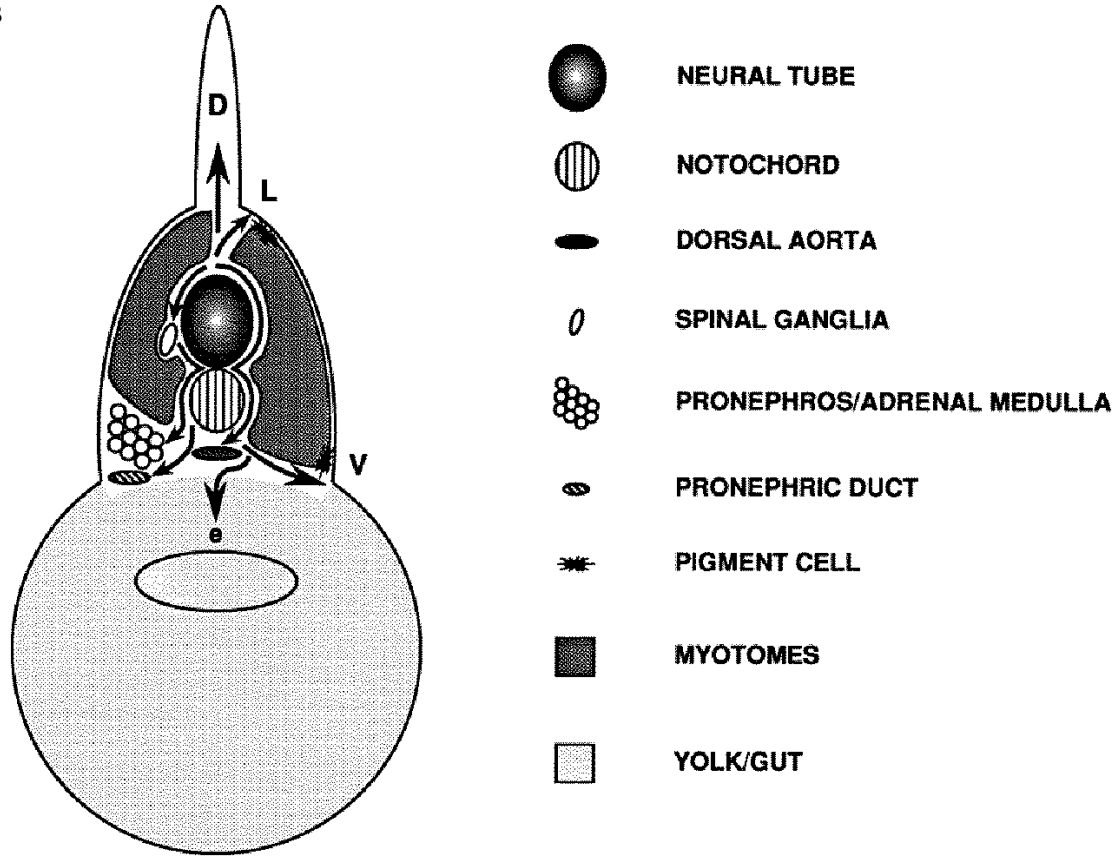

Fig. 8. Summary diagram of the derivatives to which the neural crest contributes and the paths of migration taken. (A) The trunk of an embyro is shown in four sections. The first two sections are rostral and mid trunk regions while the last two sections are caudal regions. All sections show the dorsal, ventral and lateral pathways. The rostral region illustrates migratory pathways to the pronephros/adrenal medulla and lateral pigment stripe. The middle region illustrates migratory pathways to a spinal ganglia, pronephric duct and the lateral pigment stripe. The second caudal section illustrates a migratory path to the dorsal aorta. The two paths of migration of cells into the ventral fin are labelled: (1) the tail tip pathway extending along the dorsal surface of the neural tube or within the dorsal fin, around the tip of the tail and into the ventral fin; (2) the enteric pathway proceeding ventrad towards the anus, subsequently entering the ventral fin. (B) Summary of all but the two ventral fin pathways on a transverse section illustrating all the derivatives to which the neural crest contributes; D, the dorsal pathway; L, the lateral pathway; V, the ventral pathway; e, enteric region. Pigment cells migrate along pathways $\mathrm{L}$ and $\mathrm{V}$.

\section{DISCUSSION}

In these experiments, examination of trunk neural crest migration in living Xenopus embryos confirms and extends previous studies of neural crest cell migratory pathways and derivatives (Sadaghiani and Thiebaud, 1987; Krotoski et al., 1988; Epperlein and Lofberg, 1990). Neural crest migration progresses as a wave down the embryo, starting at stage 25 in the rostral region of the embryo and at stage 28 or later in more caudal regions; it finishes by stage 41 in the rostral regions and stage 46 more caudally. In addition to the previously characterized pathways of neural crest cell migration, we find two novel paths of migration followed by the neural crest that take part in the formation of tail structures (Fig. 8). Cells taking the path around the tail migrate caudally within the dorsal fin to circumnavigate the tail tip and course rostrally along the ventral fin. Cells following the enteric pathway progress ventrally towards the anus, directly down the presumptive enteric region and into the ventral fin.

DiI-labelling experiments reveal several previously undescribed Xenopus neural crest derivatives such as the adrenal 
medulla, pronephric duct and posterior portion of the dorsal aorta, in addition to confirming other previously reported derivatives (spinal ganglia, pigment cells, fins, enteric ganglia). The range of neural crest derivatives differs with axial level. Both rostral and caudal trunk neural crest cells form pigment cells, sensory and sympathetic neurons, glia and dorsal fin cells. Unique rostral derivatives are adrenomedullary and pronephric duct cells; whereas, unique caudal derivatives are enteric, dorsal aorta and ventral fin cells. Neural crest cells first differentiate in rostral regions and then differentiation proceeds in a rostrocaudal wave as in avian and mouse embryos (Le Douarin, 1982; Serbedzija et al., 1989, 1991).

By injecting fluorescent dextran into individual precursor cells in the neural tube, we are able to gain some insights into the developmental potential of single Xenopus neural crest precursors. Our findings show that (1) dorsal neural tube and neural crest cells can share a common precursor, (2) those clones that give rise to neural crest cells often give rise to cells in multiple derivatives and (3) neural tube and neural crest clones can be bilaterally distributed in the embryo. These results in Xenopus are in general agreement with those obtained in the chick embryo using dextran injection (Bronner-Fraser and Fraser, 1988, 1989; Fraser and Bronner-Fraser, 1991) or infection with a recombinant retrovirus (Frank and Sanes, 1991). Because we categorize cell phenotype based on position and morphology, we may be underestimating the numbers of derivatives arising from a single cell. For example, our classification of 'neuronal' cells in the spinal ganglion may contain several types of neurons as well as glia and non-neuronal cells. Similarly, the classification of 'fin' cell encompasses both mesenchymal and secretory phenotypes. Thus, even clones that we list as within a single category may contain multiple phenotypes, which were not distinguished in our study. It should be remembered that terminal position alone may not be an accurate predictor of cell fate because some labelled cells present in a given neural crest derivative might undergo cell death or fail to differentiate.

As in most fate-mapping experiments, our results probably offer only a lower estimate of the developmental potential of the individual labelled cells. Although some of the clones that populated only a single derivative may have expressed the full range of their potential, many of the cells might have differentiated into a wider range of phenotypes had they been exposed to different environments. For example, we observed many clones that contributed cells only to the dorsal fin. However, until their developmental fate is challenged, perhaps by transplantation to other regions of the embryo, no conclusions about phenotypic restrictions can be drawn. Therefore, while our results offer direct evidence for the multipotentiality of some cells, our experiments cannot be taken as evidence that either supports or refutes the presence of subpopulations of neural crest cells which are unipotent.

There are some notable differences between our results in Xenopus and similar analyses in the chick. Clones in the chick migrate as closely associated sheets of numerous cells (c.f. Bronner-Fraser, 1986) and are restricted to 2 to 3 segments; whereas, those in Xenopus are fewer in number, migrate as sparse individual cells and often are spread over
8 or more myotomal segment lengths. Although the extensive axis elongation seen during development accounts for some of the dispersion in Xenopus, time-lapse films reveal that active migration is a major contributor. Extensive dispersion of clonally related cells has been reported in other systems such as the mammalian brain (Walsh and Cepko, 1992). With respect to cell migration, chick neural crest cells move through the rostral but not caudal half of each somitic sclerotome (Rickmann et al., 1985; Bronner-Fraser, 1986). In contrast, Xenopus neural crest cells migrate along a ventral pathway between the neural tube and caudal portion of each somite (Krotoski et al., 1988). In the present study, DiI-labelled cells in living embryos are observed along this pathway in dorsoventrally oriented streams, many of which then turn to migrate either rostrally or caudally. In addition to this predominant pathway, there is a minor 'lateral' pathway in Xenopus between the epidermis and somites (Sadaghiani and Thiebaud, 1987; Krotoski et al., 1988). Our results show that most of the DiI-labelled pigment cells utilize the ventral path and later move superficially by migrating between the somite and yolk to reach the epidermis. This contrasts with salamanders and avians, in which the lateral pathway is the primary pathway for pigment cell migration (Keller et al., 1982; Keller and Spieth, 1984; Serbedzija et al., 1989). The observation that few Xenopus pigment cells migrate along the lateral pathways to populate the dorsal pigment stripe highlights the potential pitfall of deducing the path of migration based on the final locations of cells. Analysis of pigment cell behavior in living embryos demonstrates that pigment cells undergo dynamic cytoplasmic movements during migration. Interestingly, not all processes of the LRD-labelled pigment cells contained melanin granules; thus, the orientation of melanin-containing processes may not be a reliable marker for directionality of cell movement (Keller and Spieth, 1984).

The cells contributing to the dorsal and ventral fins undergo the most extensive cell movements of any of the neural crest cells followed in this study. The fin is thought to form by an inductive interaction between the epidermis and the underlying neural crest (Twitty and Bodenstein, 1941). Labelled neural crest cells are observed first at or near the base of the prospective fin by stages 26 to 28 . Within the fin, which is relatively transparent, DiI-labelled cells progressively spread along the rostrocaudal axis. The dispersion of labelled cells observed during tail formation might result from active migration and/or passive transport within the tissue involved in the extensive morphogenesis. However, many of the cells in the ventral fin coursed caudorostrally, in the opposite direction expected for passive transport. In addition, the presence of labelled cells that circumnavigate the tail tip en route to the ventral fin indicates that active migration is a major mechanism for many of the cells.

The present study demonstrates the utility of performing cell marking experiments in living Xenopus embryos in order to study the migrational pathways and cell lineages of the neural crest. Because our techniques allow us to follow the same cells over time, we are able to assay cell migration and differentiation in an unperturbed system. The results expand upon earlier studies to reveal previously 
unobserved pathways of migration into the ventral fin and novel derivatives that the neural crest populates. The results show that some Xenopus neural crest cells, like their avian (Bronner-Fraser and Fraser, 1988, 1989) and their murine (Serbedzija et al., 1992) counterparts, are multipotent. The strengths of comparative analyses are that common properties, such as the multipotentiality of most premigratory neural crest cells, become apparent; differences, such as in the timing and pathways of migration for pigment cells, can help to differentiate between correlative and causal relationships. The migratory pathways and developmental potentials of Xenopus neural crest cells defined in this study, provide the groundwork in a species that is easily manipulable for experimental analyses.

We thank Tina Joe, Gary Belford, Mary Flowers and Forrest Vickery for technical assistance and Susana Cohen-Cory, Jack Sechrist, John Shih and Claudio Stern for critical reading of the manuscript. This work was supported by USPHS grants (HD25138 to M. B.-F.; HD26864 to S. E. F.) and fellowship support from the NIH (1F32NS09140-01) and the Muscular Dystrophy Association to A. C.

\section{REFERENCES}

Akira, E. and Ide, H. (1987). Differentiation of neural crest cells of Xenopus laevis in clonal culture. Pigment Cell Res. 1, 28-36.

Baroffio, A., Dupin, E. and Le Douarin, N. M. (1991). Common precursors for neural and mesectodermal derivatives in the cephalic neural crest. Development 112, 301-305.

Bronner-Fraser, M. (1986). Analysis of neural crest cell lineage and migration. Dev. Biol. 115, 44-55.

Bronner-Fraser, M. and Fraser,S. E. (1988). Cell lineage analysis reveals multipotency of some avian neural crest cells. Nature 335, 161-164.

Bronner-Fraser, M. and Fraser,S. E. (1989). Developmental potential of avian trunk neural crest cells in situ. Neuron 3, 755-766.

DuShane, G. P. (1935). An experimental study of the origin of pigment cells in Amphibia. J. Exp. Zool. 72, 1-31.

DuShane, G. P. (1938). Neural fold derivatives in the Amphibia. Pigment cells, spinal ganglia and Rohon-Beard cells. J. Exp. Zool. 78, 485-502.

Epperlein, H. H. and Lofberg, J. (1990). The development of the larval pigment patterns in Triturus alpestris and Ambystoma mexicanum. Adv. Anat. Embryol. Cell Biol. 118, 1-99.

Frank, E. and Sanes, J. R. (1991). Lineage of neurons and glia in chick dorsal root ganglia: analysis in vivo with a recombinant retrovirus. Development 111, 895-908.

Fraser, S. E. and Bronner-Fraser,M. (1991). Migrating neural crest cells in the trunk of the avian embryo are multipotent. Development 112, 913920.

Gimlich, R. L. and Braun,J. (1986). Improved fluorescent compounds for tracing cell lineage. Dev. Biol. 109, 509-14.

Hall, B. K. and Horstadius, S. (1988). The Neural Crest. New York: Oxford University Press.

Keller, R. E., Löfberg, J. and Spieth,J. (1982). Neural crest cell behavior in white and dark embryos of Ambystoma mexicanum: Epidermal inhibition of pigment cell migration in the white axolotl. Dev. Biol. 89, 179-95.

Keller, R. E. and Spieth,J. (1984). Neural crest cell behavior in white and dark larvae of Ambystoma mexicanum: Time-lapse cinemicrographic analysis of pigment cell movement in vivo and in culture. J. Exp. Zool. 229, 109-26.

Krotoski, D. M., Fraser, S. E. and Bronner-Fraser,M. (1988). Mapping of neural crest pathways in Xenopus laevis using inter- and intra-specific cell markers. Dev. Biol. 127, 119-132.

Le Douarin, N. (1982). The Neural Crest. Cambridge: Cambridge University Press.

Lumsden, A., Sprawson, N. and Graham, A. (1991). Segmental origin and migration of neural crest cells in the hindbrain region of the chick embryo. Development 113, 1281-91.

Nieuwkoop, P. D. and Faber,J. (1967). Normal Table of Xenopus laevis (Daudin). Second ed. Amsterdam: North-Holland Publishing Company.

Rickmann, M., Fawcett, J. W. and Keynes,R. J. (1985). The migration of neural crest cells and the growth of motor axons through the rostral half of the chick somite. J. Embryol. Exp. Morph. 90, 437-455.

Sadaghiani, B. and Thiebaud, C. H. (1987). Neural crest development in the Xenopus laevis embryo studied by interspecific transplantation and scanning electron microscopy. Dev. Biol. 124, 91-110.

Serbedzija, G. N., Bronner-Fraser, M. and Fraser, S. E. (1989). A vital dye analysis of timing and pathways of avian trunk neural crest cell migration. Development 106, 809-816.

Serbedzija, G. N., Bronner-Fraser, M. and Fraser, S. E. (1992). Developmental potential of neural crest cells in the mouse. Soc. Neurosci. Abstr. 18, p. 17.

Serbedzija, G. N., Burgan, S., Fraser, S. E. and Bronner-Fraser, M. (1991). Vital dye labelling demonstrates a sacral neural crest contribution to the enteric nervous system of chick and mouse embryos. Development 111, 857-866.

Serbedzija, G. N., Fraser, S. E. and Bronner-Fraser, M. (1990). Pathways of trunk neural crest cell migration in the mouse embryo as revealed by vital dye labelling. Development 108, 605-12.

Seufert, D. W. and Hall,B. K. (1990). Tissue interactions involving cranial neural crest in cartilage formation in Xenopus laevis (Daudin). Cell Differ. Dev. 32, 153-166.

Sextier-Sainte-Claire Deville, F., Ziller, C. and Le Douarin, N. (1992). Developmental potentialities of cells derived from the truncal neural crest in clonal cultures. Dev. Brain Res. 66, 1-10.

Sieber-Blum, M. and Cohen,A. M. (1980). Clonal analysis in quail neural crest cells: They are pluripotent and differentiate in vitro in the absence of noncrest cells. Dev. Biol. 80, 96-106.

Thiebaud, C. H. (1983). A reliable new cell marker in Xenopus. Dev. Biol. 93, 324-343.

Twitty, V. C. and Bodenstein, D. (1941). Experiments on the determination problem I. The roles of ectoderm and neural crest in the development of the dorsal fin in amphibia II. Changes in ciliary polarity associated with the induction of fin epidermis. J. Exp. Zool. 86, 343-380.

Walsh, C. and Cepko, C. L. (1992). Widespread dispersion of neuronal clones acrss functional regions of the cerebral cortex. Science 255, 434440.

Wetts, R. and Fraser, S. E. (1988). Multipotent precursors can give rise to all major cell types of the frog retina. Science 239, 1142-1145.

Weston, J. A. and Butler, S. L. (1966). Temporal factors affecting localization of neural crest cells in the chicken embryo. Dev. Biol. 14, 246-266. 